\title{
HUBUNGAN PERILAKU MASYARAKAT DALAM PEMBERANTASAN SARANG NYAMUK DAN FAKTOR LINGKUNGAN DENGAN KEJADIAN DEMAM BERDARAH DENGUE DI WILAYAH PUSKESMAS I DENPASAR SELATAN DAN PUSKESMAS I DENPASAR TIMUR
}

\author{
Dwi Jata ${ }^{1 *}$ Nyoman Adi Putra ${ }^{2)}$ I.B.G.Pujaastawa ${ }^{3)}$ \\ ${ }^{1)}$ Dinas Kesehatan Provinsi Bali \\ ${ }^{2)}$ Fakultas Kedokteran Universitas Udayana Denpasar \\ ${ }^{3)}$ Fakultas Sastra dan Budaya Universitas Udayana Denpasar \\ ${ }^{*}$ E-mail:dwijata11@gmail.com
}

\begin{abstract}
Dengue hemorrhagic fever (DHF) is one of diseases that causes health problems in Indonesia and oftenly creates extraordinary events with great death. The purpose of this research is to discover relationship community behavior in mosquito nesting eradication and environmental factors with DHF incidence in 1st Public Health Center Denpasar Selatan and 1st Public Health Center Denpasar Timur. The research design used is observational, cross-sectional. Total sample of 82 households. Sampling was done in proportion sampling method. Results of the analysis of environmental variables associated with DHF incidence in 1st Public Health Center Denpasar Selatan: occupant density $(p=0.02)$, mobility $(p=0.01)$, the habit of hanging clothes $(p=0.04)$. 1st Public Health Center Denpasar Timur: mobility $(p=0.00)$, clogged water ditches $(p=$ $0.00)$, containers water existance $(p=0.03)$, the habit of hanging clothes $(p=0.00)$. Knowledge, attitude and actions in 1st Public Health Center Denpasar Selatan and 1st Public Health Center Denpasar Timur statistically correlated with DHF incidence. As conclusion of the research results, in 1st Public Health Center Denpasar Selatan and 1st Public Health Center Denpasar Timur, that is mobility, the habit of hanging clothes, knowledge, attitude and actions strongly related with DHF incidence, while that is clogged water ditches, containers water existance and occupant density has no relation with DHF incidence. Public Health Center need to intensify health promotion, improves the quality of MNE (PSN), and the Provincial Health Service need to support Public Health Center on setting policies which necessary.
\end{abstract}

Keywords: Dengue, environment, behaviour, cross-sectional

\section{PENDAHULUAN}

Penyakit Demam Berdarah Dengue (DBD) merupakan salah satu penyakit yang menimbulkan masalah kesehatan masyarakat di Indonesia dan sering menimbulkan kejadian luar biasa dengan jumlah kematian yang besar. Di Indonesia nyamuk penular (vektor) penyakit DBD yang penting adalah Aedes aegypti. Tujuan penelitian ini adalah untuk mengetahui hubungan perilaku masyarakat dalam PSN dan faktor lingkungan dengan kejadian demam berdarah dengue di wilayah Puskesmas I Denpasar Selatan dan Puskesmas I Denpasar Timur . Di Indonesia nyamuk penular (vektor) penyakit DBD yang penting adalah Aedes aegypti, Aedes albopictus, dan Aedes scutellaris tetapi sampai saat ini yang menjadi vektor utama dari penyakit DBD adalah Aedes aegypti (Depkes RI, 2005b). Berdasarkan data Dinkes Kota Denpasar (2013), selama tiga tahun terakhir kasus deman berdarah di wilayah Puskesmas I Denpasar Selatan paling tinggi yaitu pada tahun 2011 tercatat 176 kasus Insidence Rate/
$\mathrm{IR}=258,2$ per 100.000 penduduk) dengan kematian sejumlah 0 orang (Case Fatality Rate/CFR $=0 \%$ ), tahun 2012 tercatat 162 kasus IR $=216$ per 100.000 penduduk) dengan kematian sejumlah 0 orang (Case Fatality Rate/CFR $=0 \%$ ) dan tahun 2013 tercatat 350 kasus IR $=424,4$ per 100.000 penduduk) dengan kematian sejumlah 1 orang (Case Fatality Rate/CFR $=0,29 \%$ ). Wilayah kerja Puskesmas I Denpasar Timur mempunyai insiden kasus demam berdarah paling rendah dibandingkan dengan wilayah Puskesmas I Denpasar Selatan dan puskesmas lainnya yang ada di wilayah Kota Denpasar. Untuk tahun 2011 tercatat 68 kasus IR= 143 per 100.000 penduduk) dengan kematian sejumlah 1 orang (Case Fatality Rate/CFR = 1,47 \%), tahun 2012 tercatat 74 kasus IR $=86,7$ per 100.000 penduduk) dengan kematian sejumlah 0 orang (Case Fatality Rate/CFR $=0 \%$ ), tahun 2013 tercatat 111 kasus $\mathrm{IR}=118,2$ per 100.000 penduduk) dengan kematian sejumlah 0 orang (Case Fatality Rate/CFR $=0 \%$ ).

Keberadaan jentik yang digambarkan dengan angka bebas jentik di wilayah Puskesmas I Denpasar 
Selatan berturut-turut selama 3 tahun terakhir pada tahun 2011 sebesar 93,40\%, tahun 2012 sebesar 94,10\% dan tahun 2013 sebesar 90,08\%, sedangkan wilayah Puskesmas I Denpasar Timur tahun 2011 sebesar 97,68\%, tahun 2012 sebesar 95,76\% dan tahun 2013 sebesar 94,67 \% (Dinkes Kota Denpasar, 2013), dengan angka bebas jentik lebih atau sama dengan 95\% diharapkan penularan demam berdarah dapat dicegah atau dikurangi (Depkes RI, 2005b).

\section{METODOLOGI}

Rancangan penelitian ini termasuk observational dengan jenis penelitian cross sectional .Besar sampel penelitian sebesar 82 KK. Masing-masing Puskesmas I Denpasar Selatan dan Puskesmas I Denpasar Timur jumlah sampel masing - masing $41 \mathrm{KK}$. Pengambilan unit analisis sampel dilakukan secara proporsi sampling. menggunakan rumus untuk populasi yang diketahui (Lemeshow,et al.1997 ). Variabel yang diteliti adalah pengetahuan, sikap, tindakan, kebiasaan gantung pakaian, keberadaan jentik, mobilitas penduduk, kepadatan penghuni, kebearadaan kontainer air yang terbuka, genangan air dan kejadian DBD. Instrumen dalam penelitian ini menggunakan checklist dan kuesioner. Analisis data dilakukan menggunakan teknik analisis univariat dan bivariat dengan uji chi-square.

\section{HASIL DAN PEMBAHASAN}

\subsection{Hasil Analisis Bivariat}

Berdasarkan hasil uji chisquare di wilayah Puskesmas I Densel dan wilayah Puskesmas I Dentim diperoleh faktor Perilaku masyarakat meliputi pengetahuan, sikap, tindakan, kebiasaan gantung pakaian dan keberadaan jentik ada hubungan dengan kejadian DBD seperti pada Tabel 1.

\subsubsection{Hubungan antara Keberadaan Jentik di Kontainer Air/TPA dengan Kejadian DBD}

Setelah dilakukan uji chi Square di peroleh nilai signifikansi di wilayah kerja Puskesmas I Densel sebesar $\mathrm{p}=0,00$ lebih kecil dari á $=5 \%(0,00<0,05)$ dan di wilayah kerja Puskesmas I Dentim sebesar $p=0,00$ lebih kecil dari á $=5 \%(0,00<0,05)$. Hal ini menunjukkan ke dua wilayah kerja Puskesmas I Densel dan Puskesmas I Dentim ada hubungan keberadaan jentik di kontainer air/TPA responden dengan kejadian DBD .Hal ini didukung oleh hasil penelitian Widia (2009), di Kelurahan Poso, Kecamatan Pacitan, yang menyimpulkan bahwa keberadaan jentik dalam kontainer air secara statistik mempunyai hubungan yang bermakna dengan kejadian DBD.

Tabel 1. Hubungan Keberadaan Jentik di Kontainer air/TPA, Pengetahuan, Sikap, Tindakan, dan Kebiasaan Menggantung Pakaian di Belakang Pintu dengan Kejadian DBD

\begin{tabular}{|c|c|c|c|c|c|c|c|c|c|}
\hline \multirow{2}{*}{ Puskesmas } & \multirow{2}{*}{ Variabel } & & \multicolumn{4}{|c|}{ Kejadian DBD } & \multicolumn{2}{|c|}{ TOTAL } & \multirow{2}{*}{ Nilai $p$} \\
\hline & & & Tidak & ada & Tidak & ada & & & \\
\hline \multirow[t]{2}{*}{ I Densel } & \multirow[t]{4}{*}{ KeberadaanJentik } & positif & 29 & 96,70 & 1 & 3,30 & 30 & 100,00 & 0,00 \\
\hline & & negatif & 1 & 9,10 & 10 & 90,90 & 11 & 100,00 & \\
\hline \multirow[t]{2}{*}{ I Dentim } & & positif & 3 & 33,30 & 6 & 66,70 & 9 & 100,00 & 0,00 \\
\hline & & negatif & 30 & 93,80 & 2 & 6,30 & 32 & 100,00 & \\
\hline \multirow[t]{2}{*}{ I Densel } & \multirow[t]{4}{*}{ Pengetahuan } & Baik & 3 & 33,30 & 6 & 66,70 & 9 & 100,00 & 0,00 \\
\hline & & Kurang & 30 & 93,80 & 2 & 6,30 & 32 & 100,00 & \\
\hline \multirow[t]{2}{*}{ I Dentim } & & Baik & 31 & 96,90 & 1 & 3,10 & 32 & 100,00 & 0,00 \\
\hline & & Kurang & 2 & 22,20 & 7 & 77,80 & 9 & 100,00 & \\
\hline \multirow[t]{2}{*}{ IDensel } & \multirow[t]{4}{*}{ Sikap } & positif & 28 & 82,40 & 6 & 17,60 & 34 & 100,00 & 0,01 \\
\hline & & negatif & 2 & 17,60 & 5 & 71,40 & 7 & 100,00 & \\
\hline \multirow[t]{2}{*}{ I Dentim } & & positif & 30 & 93,80 & 2 & 6,20 & 32 & 100,00 & 0,00 \\
\hline & & negatif & 3 & 33,30 & 6 & 1,80 & 9 & 100,00 & \\
\hline \multirow[t]{2}{*}{ I Densel } & \multirow[t]{4}{*}{ Tindakan } & Baik & 27 & 87,10 & 4 & 12,90 & 31 & 100,00 & 0,00 \\
\hline & & Kurang & 3 & 30,0 & 7 & 70,00 & 10 & 100,00 & \\
\hline \multirow[t]{2}{*}{ I Dentim } & & Baik & 32 & 88,90 & 4 & 11,10 & 36 & 100,00 & 0,00 \\
\hline & & Kurang & 1 & 20,00 & 4 & 80,00 & 5 & 100,00 & \\
\hline \multirow[t]{2}{*}{ I Densel } & Kebiasaan & Tidak ada & 26 & 81,30 & 6 & 18,80 & 32 & 100,00 & 0,04 \\
\hline & Gantung pakaian & Ada & 4 & 44,40 & 5 & 55,60 & 9 & 100,00 & \\
\hline \multirow[t]{2}{*}{ I Dentim } & & Tidak ada & 28 & 96,60 & 1 & 3,40 & 29 & 100,00 & 0,00 \\
\hline & & Ada & 5 & 41,70 & 7 & 58,30 & 12 & 100,00 & \\
\hline
\end{tabular}


Tabel 2 Hubungan Hasil Analisis Bivariat Hubungan Lingkungan (Kepadatan Penghuni, Mobilitas, Keberadaan Kontainer Air yang Terbuka dan Genangan Air) dengan Kejadian DBD

\begin{tabular}{|c|c|c|c|c|c|c|c|c|c|}
\hline \multirow{2}{*}{ Puskesmas } & \multirow{2}{*}{ Variabel } & & \multicolumn{4}{|c|}{ Kejadian DBD } & \multicolumn{2}{|c|}{ TOTAL } & \multirow{2}{*}{ Nilai $p$} \\
\hline & & & Tidak & ada & Tidak & ada & & & \\
\hline \multirow[t]{2}{*}{ I Densel } & \multirow[t]{4}{*}{ Kepadatan Penghuni } & Tidak padat & 27 & 81,80 & 6 & 18,20 & 33 & 100,00 & 0,02 \\
\hline & & Padat & 3 & 37,50 & 5 & 62,50 & 8 & 100,00 & \\
\hline \multirow[t]{2}{*}{ I Dentim } & & Tidak padat & 28 & 84,80 & 5 & 15,20 & 33 & 100,00 & 0,17 \\
\hline & & Padat & 5 & 62,50 & 3 & 37,50 & 8 & 100,00 & \\
\hline \multirow[t]{2}{*}{ I Densel } & \multirow[t]{4}{*}{ Mobilitas Penduduk } & Rendah & 26 & 83,90 & 5 & 16,10 & 31 & 100,00 & 0,01 \\
\hline & & Tinggi & 4 & 40,00 & 6 & 60,00 & 10 & 100,00 & \\
\hline \multirow[t]{2}{*}{ I Dentim } & & Rendah & 31 & 93,90 & 2 & 6,10 & 33 & 100,00 & 0,00 \\
\hline & & Tinggi & 2 & 25,00 & 6 & 75,00 & 8 & 100,00 & \\
\hline \multirow[t]{2}{*}{ I Densel } & Keberadaan & 0 & 0 & 0 & 0 & 0 & 0 & 1,00 & \\
\hline & $\begin{array}{l}\text { kontainer air } \\
\text { yang terbuka }\end{array}$ & Tidak ada & $1-3$ & 18 & 72,00 & 7 & 28,00 & 25 & 100,00 \\
\hline \multirow[t]{4}{*}{ I Dentim } & & $>3$ & 12 & 75,00 & 4 & 25,00 & 16 & 100,00 & 0,03 \\
\hline & & Tidak ada & 1 & 100,00 & 0 & 0 & 1 & 100,00 & \\
\hline & & $1-3$ & 6 & 54,50 & 5 & 45,50 & 11 & 100,00 & \\
\hline & & $>3$ & 26 & 89,70 & 3 & 10,30 & 29 & 100,00 & \\
\hline \multirow[t]{2}{*}{ I Dentim } & Genangan Air & Tidak ada & 26 & 76,50 & 8 & 23,50 & 34 & 100,00 & 0,36 \\
\hline & & ada & 4 & 57,10 & 3 & 42,90 & 7 & 100,00 & \\
\hline \multirow[t]{2}{*}{ | Densel } & & Tidak ada & 31 & 91,20 & 3 & 8,80 & 34 & 100,00 & 0,00 \\
\hline & & ada & 2 & 28,60 & 5 & 71,40 & 7 & 100,00 & \\
\hline
\end{tabular}

\subsubsection{Hubungan antara Pengetahuan dengan Kejadian DBD}

Hasil uji chi square di peroleh nilai signifikansi di wilayah kerja Puskesmas I Densel sebesar $\mathrm{p}=0,00$ lebih kecil dari á $=5 \%(0,00<0,05)$ dan di wilayah kerja Puskesmas I Dentim sebesar $\mathrm{p}=0,00$ lebih kecil dari á $=5 \%(0,00<0,05)$. Hal ini menunjukkan ke dua wilayah kerja puskesmas ada hubungan antara tingkat pengetahuan dengan kejadian DBD.Hal ini sejalan dengan penelitian Duma et al.(2007) dalam penelitiannya menyatakan bahwa pengetahuan berhubungan secara bermakna $(\mathrm{p}=0,04$ dan $\mathrm{OR}=$ 1,71) dengan kejadian DBD.

\subsubsection{Hubungan Sikap dengan Kejadian DBD}

Hasil uji chi square di peroleh nilai signifikansi di wilayah kerja Puskesmas I Densel sebesar $p=0,01$ lebih kecil dari á $=5 \%(0,01<0,05)$ dan di wilayah kerja Puskesmas I Dentim sebesar $\mathrm{p}=0,00$ lebih kecil dari á $=5 \%(0,00<0,05)$. Penelitian ini sejalan dengan yang disampaikan oleh Azwar (2007), yang menyatakan bahwa sikap yang diperoleh lewat pengalaman akan menimbulkan pengaruh langsung terhadap perilaku berikutnya.

\subsubsection{Hubungan Tindakan dengan Kejadian DBD}

Analisis bivariat hubungan antara tindakan responden dengan kejadian DBD dengan uji statistik chi square diperoleh di peroleh nilai signifikansi di wilayah kerja Puskesmas I Densel sebesar $\mathrm{p}=0,00$ lebih kecil dari á $=5 \%(0,00<0,05)$ dan di wilayah kerja Puskesmas I Dentim sebesar $\mathrm{p}=0,00$ lebih kecil dari á $=5 \%(0,00<0,05)$. Hasil ini sejalan dengan hasil beberapa penelitian sebelumnya seperti penelitian yang dilakukan oleh Ririh dan Anny (2005), yang menyatakan bahwa ada hubungan bermakna antara tindakan responden dalam upaya PSN DBD dan abatisasi dengan keberadaan jentik di rumahnya (nilai $\mathrm{p}=0,001$ ),

\subsubsection{Hubungan Kebiasaan Gantung Pakaian dengan Kejadian DBD}

Hasil penelitian uji chi square diperoleh nilai signifikansi di wilayah kerja Puskesmas I Densel sebesar $\mathrm{p}=0,04$ lebih kecil dari á $=5 \%(0,04<0,05)$ dan di wilayah kerja Puskesmas I Dentim sebesar $\mathrm{p}=0,00$ lebih kecil dari á $=5 \% \quad(0,00<0,05)$. Penelitian Presti (2011), di Kecamatan Tembalang Kota Semarang, bahwa ada hubungan bermakna antara kebiasaan menggantung pakaian dengan kejadian DBD $(\mathrm{OR}=2,923(\mathrm{CI}=1,142-7,482)$.

\subsection{Hubungan Hasil Analisis Bivariat, Hubungan Lingkungan (Kepadatan Penghuni, Mobilitas, Keberadaan Kontainer Air yang Terbuka dan Genangan Air) dengan Kejadian DBD}

\subsubsection{Kepadatan Penghuni}

Hasil uji chi square diperoleh nilai signifikansi di wilayah kerja Puskesmas I Densel sebesar $\mathrm{p}=0,02$ lebih kecil dari á $=5 \%(0,02<0,05)$ dan di wilayah kerja Puskesmas I Dentim se4besar $\mathrm{p}=0,17$ lebih 
besar dari á $=5 \%(0,17>0,05)$. Hal ini menunjukkan wilayah kerja Puskesmas I Densel ada hubungan antara kepadatan penghuni dengan kejadian DBD sedangkan hasil penelitian wilayah kerja Puskesmas I Dentim tidak ada hubungan antara kepadatan penghuni dengan kejadian DBD pada Tabel 2. Hasil analisis chi square yang diperoleh di wilayah Puskesmas I Densel nilai $\mathrm{p}=0,02(\mathrm{p}<\mathrm{a})$, hasil penelitian ini ada hubungan kepadatan penghuni dengan kejadian demam berdarah. Hal ini sesuai dengan laporan dari Departemen Kesehatan RI (Depkes RI, 2000) di mana kepadatan penduduk turut menunjang atau sebagai salah satu faktor resiko penularan penyakit DBD. Semakin padat penduduk, semakin mudah nyamuk Aedes aegypti menularkan virusnya dari satu orang ke orang lainnya.

\subsubsection{Mobilitas Penduduk}

Hasil uji chi square di peroleh nilai signifikansi di wilayah kerja Puskesmas I Densel sebesar $p=0,01$ lebih kecil dari á $=5 \%(0,01<0,05)$ dan di wilayah kerja Puskesmas I Dentim sebesar $\mathrm{p}=0,00$ lebih kecil dari á $=5 \%(0,00<0,05)$. Hal ini menunjukkan ke dua wilayah kerja Puskesmas I Densel dan wilayah kerja Puskesmas I Dentim ada hubungan antara mobilitas responden dengan kejadian DBD.

Hasil ini sesuai dengan pendapat Sunaryo (1988) yang menyebutkan bahwa mobilitas penduduk memudahkan penularan dari satu tempat ke tempat lainnya.

\subsubsection{Keberadaan Kontainer Air yang Terbuka}

Hal ini menunjukkan di wilayah kerja Puskesmas I Densel tidak ada hubungan antara keberadaan kontainer air yang terbuka seperti bak mandi/WC, tempayan/gentong, ember dan lain-lain dengan kejadian DBD. Hal ini berkaitan dengan perilaku masyarakat yang ditunjukkan dengan frekuensi dan kualitas PSN DBD yang sudah baik yakni 31 responden (75,60 \%) dan didukung kebiasaan tidak menggantung pakaian di belakang pintu yang dalam keadaan kondisi lembab baik di kamar mandi maupun di kamar tidur yakni 32 responden (78\%).

\subsubsection{Genangan Air}

Hasil uji chi square di peroleh nilai signifikansi di wilayah kerja Puskesmas I Densel sebesar $p=0,36$ lebih besar dari á $=5 \%(0,36>0,05)$ dan di wilayah kerja Puskesmas I Dentim sebesar $\mathrm{p}=0,00$ lebih kecil dari á $=5 \%(0,00<0,05)$. Hal ini menunjukkan bahwa di wilayah kerja Puskesmas I Densel tidak ada hubungan antara genangan air di sekitar rumah seperti selokan/got dengan kejadian DBD, sedangkan di wilayah kerja Puskesmas I Dentim ada hubungan antara genangan air dengan kejadian DBD. Genangan air di sekitar rumah seperti selokan/ got pada musim penghujan merupakan tempat perindukan yang baik bagi jentik nyamuk penular Aedes aegypti. Mewabahnya demam berdarah berkait erat dengan meledaknya populasi nyamuk saat banyak turun hujan, sebab intensitas hujan yang tinggi turut memicu perkembangan populasi nyamuk

\section{SIMPULAN DAN SARAN}

\subsection{Simpulan}

1) Faktor perilaku masyarakat dalam PSN yang ada hubungan dengan kejadian DBD di wilayah kerja Puskesmas I Densel dan Puskesmas I Dentim yaitu pengetahuan tentang penyakit DBD dan cara pengendalian meliputi pencegahan dan pemberantasan nyamuk penular DBD, sikap terhadap upaya pemberantasan sarang nyamuk penular DBD, tindakan dalam pelaksanaan pemberantasan sarang nyamuk penular demam berdarah dengue (3 M plus), kebiasaan menggantung pakaian yang dalam kondisi lembab di belakang pintu kamar mandi/ kamar tidur dan keberadaan jentik di bak kamar mandi/wc, tempayan/gentong, ember dan lain-lain

2) Faktor lingkungan yang ada hubungan dengan kejadian DBD di wilayah kerja Puskesmas I Densel yaitu mobilitas penduduk dan kepadatan penghuni sedangkan untuk wilayah kerja Puskesmas I Dentim yaitu mobilitas penduduk, kontainer air yang terbuka seperti bak kamar mandi/WC, gentong/tempayan dan lain-lain, dan genangan air seperti selokan/got.

3) Faktor lingkungan tidak ada hubungan dengan kejadian DBD di wilayah kerja Puskesmas I Dentim yaitu kepadatan penghuni sedangkan di wilayah kerja Puskesmas I Densel yaitu genangan air seperti selokan/got dan keberadaan kontainer air yang terbuka seperti bak kamar mandi/WC, tempayan/gentong, ember dan lainlain.

\subsection{Saran}

Berdasarkan kesimpulan yang didapat, maka saran yang dapat diberikan kepada masyarakat dan instansi terkait adalah:

1) Untuk masyarakat diharapkan tindakan yang bersifat preventif melalui menghindari kebiasaan menggantung pakaian yang dalam kondisi lembab di belakang pintu kamar mandi/ kamar tidur yang biasanya sebagai tempat peristirahatan nyamuk, menguras dan menyikat TPA seperti bak mandi/wc, drum seminggu sekali, menutup rapat-rapat TPA/ kontainer yang berisi air seperti gentong air/ tempayan, mengubur atau menyingkirkan barang-barang bekas yang dapat menampung 
air hujan serta mengganti air vas bunga, tempat minuman burung seminggu sekali dan TPA yang tidak bisa dikuras dengan memelihara ikan kepala timah, ikan gufi pada kolam.

2) Penyuluhan dan penyampaian informasi yang intensif tentang pencegahan dan penanggulangan penyakit DBD melalui media massa, sekolah, kader PKK atau kelompok masyarakat lainnya.

3) Perlu dilakukan pengawasan terhadap faktor lingkungan yang berhubungan dengan keberadaan jentik nyamuk penular DBD seperti keberadaan genangan air hujan di sekitar rumah, keberadaan kontainer yang berisi air yang kondisinya terbuka seperti bak mandi/wc, ember, tempayan di sekitar rumah dengan lebih mengaktifkan pengamatan jentik berkala.

\section{DAFTAR PUSTAKA}

Azwar, S. 2007. Pengantar Psikologi Intelegensi. Jakarta : Pustaka Pelajar.

Depkes RI.2000. Pencegahan dan Penanggulangan Penyakit Demam Berdarah Dengue. Terjemahan dari WHO Regional Publication SEARO No. 29 "Prevention Control of Dengue and Dengue Haemorrhagic Fever"

Depkes RI.2005b. Pencegahan dan Pemberantasan Demam Berdarah Dengue di Indonesia. Jakarta: Ditjen PPM dan PL Depkes RI.
Dinkes Kota Denpasar.2013. Laporan Tahunan Dinas Kesehatan Kota Denpasar. Denpasar: Dinas Kesehatan Kota Denpasar.

Duma, N., Darmawansyah dan A.Arsin.2007. Analisis yang Berhubungan dengan Kejadian DBD di Kecamatan Baruga Kota Kendari. Jurnal Analisis 1(2):91-100.

Lemeshow S., David W.Hosmer Jr., Janelle Klar dan Stephen K. Lwanga.1997. Besar Sampel dalam Penelitian Kesehatan. Penyunting : Kusnanto, H. Yogyakarta : Gadjah Mada University Press.

Presti, A. 2011. “Analisis Faktor Resiko yang Berhubungan dengan Kejadian Demam Berdarah Dengue (DBD) di Kecamatan Tembalang Kota Semarang"(tesis). Semarang : Universitas Negeri Semarang

Ririh, Y. dan Anny, V.2005. "Hubungan Kondisi Lingkungan, Kontainer, dan Perilaku Masyarakat dengan Keberadaan Jentik Nyamuk Aedes Aegypti di Daerah Endemis Demam Berdarah Dengue". Surabaya: Jurnal Kesehatan Lingkungan 1(2) : 170-182.

Sunaryo, S.1988.Demam Berdarah Dengue pada Anak. Jakarta: Universitas Indonesia.

Widia, E. 2009. "Beberapa Faktor yang Berhubungan dengan Kejadian Demam Berdarah Dengue (DBD) di Kelurahan Ploso Kecamatan Pacitan"(skripsi). Surakarta : Program Studi Kesehatan Masyarakat Fakultas Ilmu Kesehatan Universitas Muhammadiyah. 